\title{
Primary Cutaneous Mucinous Carcinoma of the Eyelid
}

\author{
Min Sung Tak ${ }^{1}$, \\ Seong Eun $\mathrm{Cho}^{1}$, \\ Sang Gue Kang', \\ Chul Han Kim ${ }^{1}$, \\ Dong Won Kim ${ }^{2}$
}

Departments of ${ }^{1}$ Plastic and Reconstructive

Surgery and ${ }^{2}$ Pathology, Soonchunhyang

University Seoul Hospital, Soonchunhyang

University College of Medicine, Seoul, Korea

No potential conflict of interest relevant to this article was reported.
Primary cutaneous mucinous carcinoma (PCMC) is a rare low-grade malignant neoplasm derived from the eccrine glands. PCMC most commonly arises in the head and neck, with the eyelid being the most common site of origin. This case report describes a 51-year-old male with a painless, pigmented superficial nodular lesion over his right lower eyelid. The lesion was considered to be benign, and the initial treatment was simple excision with a 3-mm margin. However, histologic examination revealed the diagnosis of PCMC, and the patient underwent re-excision of the tumor site with an additional 3-mm margin from the initial scar. Histologic study of this second margin was free of any malignant cells. The patient experienced no postoperative complication or recurrence after 2 years. In our case, the skin lesion had benign morphologic findings and was strongly suspected to be a benign mass. Physicians should be aware of this tumor and be able to differentiate it from benign cystic or solid eyelid lesions.

Keywords: Primary cutaneous mucinous carcinoma / Immunochemistry staining / Skin cancer

\section{INTRODUCTION}

Primary cutaneous mucinous carcinoma (PCMC) is a rare lowgrade malignant neoplasm derived from the eccrine glands [1]. These carcinomas most commonly arise in the head and neck region, with the eyelid being the most common site of origin [2]. It is slightly more common in men and appears most frequently between the ages of 50 and 70 years [3]. The prevalence is higher in white patients (77.2\%) than in Asians (12.7\%) or in African Americans (10.1\%) [4]. We report a case of PCMC of the lower eyelid in a 51-year-old Asian male.

\section{CASE REPORT}

\footnotetext{
Correspondence: Min Sung Tak

Department of Plastic and Reconstructive Surgery, Soonchunhyang University Seoul Hospital, Soonchunhyang University College of Medicine, 59 Daesagwan-ro, Yongsangu, Seoul 04401, Korea

E-mail: tarkms@schmc.ac.kr

*This work was supported by the Soonchunhyang University Research Fund.

Received March 10, 2016 / Revised July 5, 2016 / Accepted July 10, 2016
}

A 51-year-old male patient presented to the outpatient clinic with a painless nodule near the right lower eyelid. The mass had grown slowly over the past 3 years, and measured $0.9 \times 0.7 \mathrm{~cm}$ during examination (Fig. 1). The lesion appeared benign in clinical examination, and under local anesthesia, the patient underwent a 3-mmmargin elliptical excision and primary closure. Histologic study of this first specimen revealed epithelial cell islands floating in a mucin lake, with the final diagnosis being mucinous carcinoma. The epithelial component showed a solid and cribriform growth pattern and the tumor cells revealed moderate nuclear atypia and a

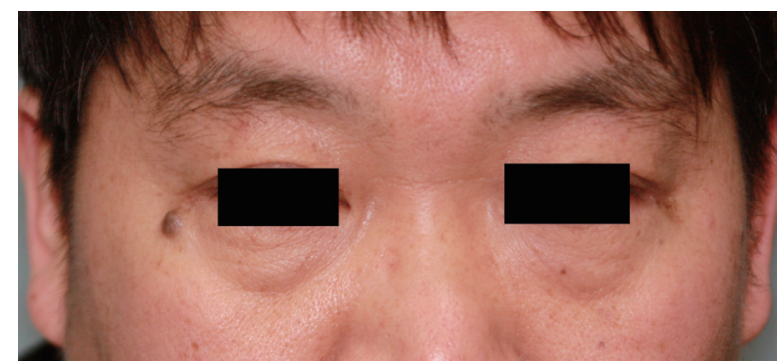

Fig. 1. Preoperative photograph of the patient with a right lower eyelid mass. 

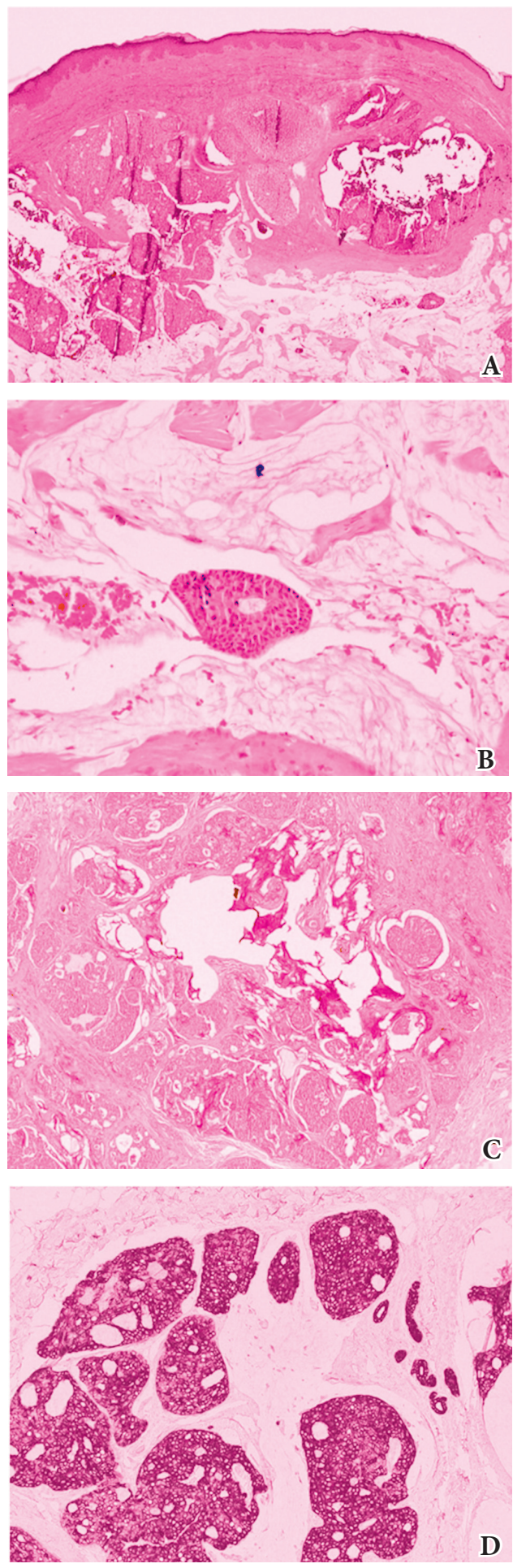

Fig. 2. Histologic examination of the first surgical specimen. (A) The tissue contains nests of epithelial cells and an abundant mucin lake (H\&E, $\times 40)$. (B) A nest of epithelial cells is floating in the mucin lake (H\&E, $\times 200)$. (C) The mucin is periodic acid-Schiff-positive and diastase-resistant. (D) Immunohistochemically, the tumor cells are positive for cytokeratins 7 .

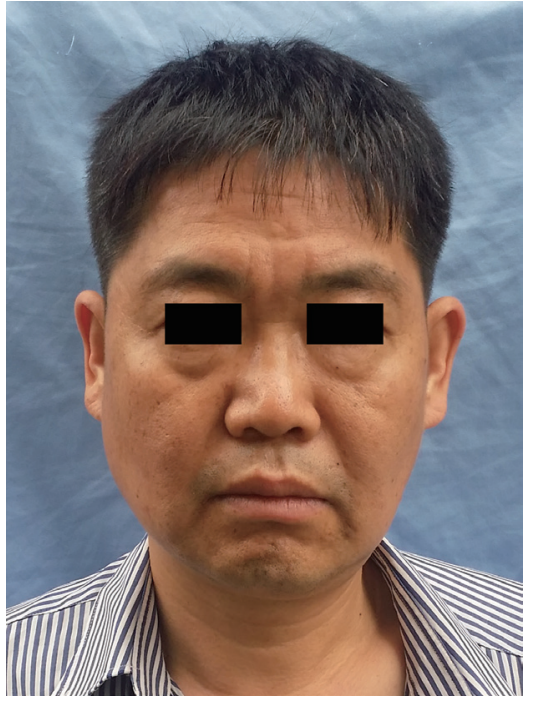

Fig. 3. Postoperative photograph. At 2-year follow-up, the patient was without any signs of recurrence or complication.

mitotic aspect. Additional immunostaining study revealed that the tumor cells were immunopositive for cytokeratins (CK)-7 and negative for CK-20 with 10\% Ki-67 positivity in the active area (Fig. 2). We performed re-excision of the surgical site with an additional 3-mm margin, which was free of malignant histology. The possibility of a metastatic primary mucinous carcinoma (e.g., breast or gastrointestinal tract) could not be completely ruled out, but a systemic evaluation by positron emission tomography-computed tomography revealed no other suspected site of malignancy. During a close follow-up over 2 years, the patient did not experience any postoperative complication or recurrence (Fig. 3).

\section{DISCUSSION}

PCMC was first described by Lennox et al. [1] and is a rare subtype of sweat gland tumor. Controversy about the apocrine or eccrine origins of this tumor has existed, but most authors favor eccrine differentiation as the origin [5]. The affected population tends to be older, in the range of 50 to 70 years [3,4]. Clinically, PCMCs have been characterized as slow-growing (with a duration of several months to several years), painless, $0.7-2.5 \mathrm{~cm}$ in size, nodular, pigmented lesions that may be ulcerated, crusted or with telangiectasis [6-8]. The single most common site is the periorbital region 
(40\%) and over half of those are lower eyelid lesions [2,9].

PCMC is a sharply circumscribed tumor in the dermis and subcutis with no connection to the epidermis [10]. Because of its location, PCMC must be differentiated from sebaceous gland and other sweat gland carcinomas, which have far less favorable prognoses, and also from basal cell carcinoma, keratoacanthoma, and nevi including vascular lesions such as Kaposi sarcoma $[7,8,10]$. Differentiation may be based on the expression pattern of CK. Eccrine mucinous carcinomas are CK-7 positive and CK-20 negative, unlike metastases of the gastrointestinal tract, which are CK-20 positive and CK-7 negative [11]. In addition, skin metastases normally contain atypical cells, exhibit increased mitotic activity, and are usually surrounded by collagen bundles [12].

Primary mucinous carcinoma of the skin has a relatively good prognosis with lower rates of distant metastases $(9.6 \%$, commonly to regional lymph nodes), but local recurrence rate is higher at $29.4 \%[6,13]$. Since the 1979 study by Wright and Font [2], PCMC of the eyelid has been regarded as having high rates of recurrence (up to $40 \%$ ). In a more recent study, in 2004, Marra et al. [14] reported a recurrence rate of $34 \%$ in the eyelid.

PCMC is resistant to chemotherapy and radiotherapy [15]. The treatment recommendation has been surgical excision with a minimum of 10-mm margin [6,16,17]. Morbidity from PCMC of the eyelid is associated with incompletely resections [18]. However, some authors have suggested Moh's micrographic surgery as an alternative to wide local excision. The tumors have a natural history of local invasion, and this risk remains high despite the use of Moh's surgery [19]. In a report by Bindra et al. [20], a patient presented with a PCMC that involved the lower eyelid in its entirety. The authors reported that wide surgical margins would be prohibitively morbid and instead opted for a 5-mm margin, which were free of malignant cells on histologic exam.

At our first operation, we excised the tumor with a simple 3-mm margin because the lesion appeared to be benign. However, histologic examination revealed the diagnosis of PCMC, and the patient underwent re-excision of the tumor site with an additional 3-mm margin from the initial scar. A wider surgical margin (i.e., $10 \mathrm{~mm}$ ) was not acceptable to the patient who was worried about the resulting scar. We also thought that a wide excision could result in excessive facial scar, due to flap procedure, and also become a cause for ectropion. The patient was followed closely for 2 years, during which he experienced neither postoperative complications nor recurrence.

PCMC is a rare malignancy that can present as a benign skin lesion. Physicians should be aware of this tumor and be able to differentiate it from benign cystic or solid eyelid lesions.

\section{REFERENCES}

1. Lennox B, Pearse AG, Richards HG. Mucin-secreting tumours of the skin with special reference to the so-called mixed-salivary tumour of the skin and its relation to hidradenoma. J Pathol Bacteriol 1952;64 :865-80.

2. Wright JD, Font RL. Mucinous sweat gland adenocarcinoma of eyelid: a clinicopathologic study of 21 cases with histochemical and electron microscopic observations. Cancer 1979;44:1757-68.

3. Mendoza S, Helwig EB. Mucinous (adenocystic) carcinoma of the skin. Arch Dermatol 1971;103:68-78.

4. Kamalpour L, Brindise RT, Nodzenski M, Bach DQ, Veledar E, Alam M. Primary cutaneous mucinous carcinoma: a systematic review and meta-analysis of outcomes after surgery. JAMA Dermatol 2014; 150:380-4.

5. Carson HJ, Gattuso P, Raslan WF, Reddy V. Mucinous carcinoma of the eyelid: an immunohistochemical study. Am J Dermatopathol 1995;17:494-8.

6. Scilletta A, Soma PF, Grasso G, Scilletta R, Pompili G, Tarico MS, et al. Primary cutaneous mucinous carcinoma of the cheek: case report. G Chir 2011;32:323-5.

7. Papalas JA, Proia AD. Primary mucinous carcinoma of the eyelid: a clinicopathologic and immunohistochemical study of 4 cases and an update on recurrence rates. Arch Ophthalmol 2010;128:1160-5.

8. Liszauer AD, Brownstein S, Codere F. Mucinous eccrine sweat gland adenocarcinoma of the eyelid. Can J Ophthalmol 1988;23:17-21.

9. Warycha M, Kamino H, Mobini N, Hale EK. Primary mucinous carcinoma with direct histopathologic evidence of lymphatic invasion. J Drugs Dermatol 2006;5:655-8.

10. Scholz IM, Hartschuh W. Primary mucinous eccrine carcinoma of the skin: a rare clinical tumor with many differential diagnoses. J Dtsch Dermatol Ges 2010;8:446-8.

11. Eckert F, Schmid U, Hardmeier T, Altmannsberger M. Cytokeratin expression in mucinous sweat gland carcinomas: an immunohistochemical analysis of four cases. Histopathology 1992;21:161-5.

12. Snow GB, Clark JR, Andersen JW. Multimodality therapy for head and neck cancer. New York: Thieme Medical Publishers; 1992.

13. Sudesh R, Siddique S, Pace L. Primary eyelid mucinous adenocarcinoma of eccrine origin. Ophthalmic Surg Lasers 1999;30:394-5.

14. Marra DE, Schanbacher CF, Torres A. Mohs micrographic surgery of 
primary cutaneous mucinous carcinoma using immunohistochemistry for margin control. Dermatol Surg 2004;30:799-802.

15. Maerki J, Ahmed S, Lee E. Primary mucinous carcinoma of the skin. Eplasty 2013;13:ic47.

16. Lee GA, Cominos D, Sullivan TJ. Clinicopathological report: mucinous carcinoma of the eyelid. Aust NZJ Ophthalmol 1999;27:71-3.

17. Krishnakumar S, Rambhatla S, Subramanian N, Mahesh L, Biswas J. Recurrent mucinous carcinoma of the eyelid. Indian J Ophthalmol
2004;52:156-7.

18. Cohen KL, Peiffer RL, Lipper S. Mucinous sweat gland adenocarcinoma of the eyelid. Am J Ophthalmol 1981;92:183-8.

19. Durairaj VD, Hink EM, Kahook MY, Hawes MJ, Paniker PU, Esmaeli B. Mucinous eccrine adenocarcinoma of the periocular region. Ophthal Plast Reconstr Surg 2006;22:30-5.

20. Bindra M, Keegan DJ, Guenther T, Lee V. Primary cutaneous mucinous carcinoma of the eyelid in a young male. Orbit 2005;24:211-4. 